\title{
THE POWER OF ONLINE MEDIA: CRITICAL DISCOURSE ANALYSIS OF SECURITY CRITICS
}

\author{
Afriliani $^{* *}$, Untung Yuwono ${ }^{1}$ and Bernadette Kushartanti ${ }^{1}$ \\ ${ }^{1}$ Universitas Indonesia, Indonesia
}

\begin{abstract}
Security issue has become the most reported headline in mass media. This issue is categorized as hard news, which is covered and reported as soon as it happens. All aspects which are written and displayed in the text could influence the readers. Although many believe that news exist to inform the reader, news can be misled and contain specific point of view toward some issues. Critical discourse analysis becomes the tool to find out how editor use their power in composing text. This research is using qualitative method to a text from online media talking about security critics. As for verbal aspect, researcher is using appraisal theory (Martin and White, 2005) and for nonverbal aspect is using news value of photography by Caple (2013). The result is the differences in distribution in negativity aspects as the verbal one carries more negative aspects than the nonverbal. The result also shows how the writer and editor's position and tendency toward the event in reporting news such as negative judgment.
\end{abstract}

Keywords: critical discourse analysis, multimodality, appraisal, and visual value.

\section{Introduction}

News text can spread certain stereotype that influences the readers of some issues. The typical kind of text used for stirring reader thought is critical text. This text contains sharp critic from writer. A critical text usually publishes under editorial column; however, in this case, critical text is published under common news column. If an editorial contains independent review of a writer, critical text in news column contains thoughts from several sources. Security issue in critical discourse analysis become important because it's high sensitivity in viewing humanity aspect. Society will receive a point of view from a critical text that will make prejudice among society about true and false. The prejudice that related to critic of humanity aspect will give fatal impact if the news is reported by imbalance facts. News can give benefit to one party and can harm another party. It will become worse if the news is misleading the reader from the actual event. Moreover, in this case, a text is published worldwide in online media and consumed by hundreds millions of people. By the massive publication and the acceleration of the speed of the news flow, It makes its impact bigger (McNair, 2006). How the editor positioning his/her point of view can be seen through power-display (Bazzi, 2009). Power-display is one of the results of critical discourse analysis from making a conclusion of analysis using multimodality. Multimodality approach itself is an approach in critical discourse analysis that investigates the relationship among modes in and out of linguistics in order to create meaning of communication (Elleström, 2010). Semiotic mode (modality) in communication can be written language, oral language, image, gesture, sculpture, and many more.

This research is a case study which is part of the researcher's thesis. The research is about a text that contains critic toward The Philippines President, Duterte. This article contains critics from many parties. The researcher wants to seek how journalist delivers his critics to reader with considering objectivity and truth of the news. According to Thomson, E.A., White, P.R.R, \& Kitley, P. (2008) the neutrality and objectivity are having deal with linguistic aspects of reaching out how the text composed and the culture perceived. The researcher wants to compare two form analysis using verbal modality and nonverbal modality. The two modalities work together to build the meaning. Comprehending both modes make the research more capable to see a full picture about the meaning of the text, implicitly and explicitly. The finding from analysis multimodal will be cross-checked with the ethics in journalism in order to find out how the combination of linguistics and image meaning have 
correlation value in journalism such as objectivity of the text and to find out how impactful or powerful the text to influence the society.

Before working in this research, researcher has been doing other type of critical discourse analysis of an editorial. The previous research becomes pilot project to find out what is missing in critical discourse analysis; the result finds the importance of including other mode beside language aspect. The previous study shows author idea cannot be covered holistically in investigating written mode alone so the feedback from the readers are still negative meanwhile the article's purpose is giving positive insight about the mislead of terrorism issues with certain religion (Afriliani, 2016). Next previous study about critical discourse analysis is by Knox J.S., Patpong P. and Piriyasilpa Y. (2010). They are using appraisal theory and visual grammar for newspaper front page in Thailand. Although the previous researches have implemented visual aspect, some are not considering the value of image yet. For education purpose, researcher also has conducted a mini research about writing text for students by making use photo gallery (Afriliani, 2017a). The study for education considers the value of image but limited only to give the input to student of the strategy in using communication modes for creating and comprehending a text. Multimodality is also benefiting in analysing market for product by using corpus data (Thomas, 2014). By how multimodality giving benefit to society, the research is aiming to offer the holistic finding of certain issues attached in a region so that it can help and improve the quality in life of society in certain region and making a better perspective of the citizen of the world in perceiving the issue.

\section{Theory}

Online text is a multimodal text. This text not only contains verbal modality and also nonverbal modality such as pictures, graph, and diagram. Multimodality is a representation from many modalities (Kress, 2010). In critical discourse analysis toward multimodal text, it is important to keep the balance by working in both modalities, verbal and nonverbal. News text is called multimodal text because multimodal approach combines verbal and nonverbal modalities equally. Previous research such as Kress and van Leeuwen (2006) has been succeeding in combining verbal mode and nonverbal (visual) mode in multimodal approach. Other researchers such as Baldry and Thibault (2006) have been used multimodality for video and script. These researchers are able to develop the research framework more systematic and detailed. Their framework tries to describe, classify, and explain what critical discourse analysis doing in modality of verbal like language and nonverbal or outside language. Critical discourse analysis based on Machin and Mayr (2012) is useful for revealing ideology like hegemony, power and domination and it is able in describing the linguistics pattern of the text. It is also useful as a research tool in order analyzing language and picture more systematic.

\section{Appraisal}

In order to understand the meaning of news text from its language form, it involves a process called appraisal. Appraisal in cognitive system is seen as a tool assesses to which degree ego is involved (Read and Carroll, 2012). In this paper, researcher used appraisal theory based on analysis in systemic functional linguistic by Halliday (1994). The source of appraisal theory is by ideational metafuction in language or could be called as shared experience (Knapp and Watkins, 2005). Then, the theory has been developed by researchers such as Martin, White, and Rose (2005, 2007). Appraisal theory offer more comprehensive system analysis in expressing subjective opinion and realizing from inter-subjective strategy. Martin and White (2005) said appraisal is defined as a source of semantics system to respond emotionally/affect, to judge the moral/judgment, and evaluate aesthetic/appreciation.

Appraisal stands for three part of evaluation. Those are attitude, engagement and graduation. Attitude is feeling including emotional reaction, behavioural assessment, and things evaluation. Engagement relate to the source of attitude and how source of attitude played in construct discourse. Graduation has function as evaluation to grade phenomenon in which the feeling can be amplified. In this paper, the research more focus to find the attitude of the text since attitude of the text will be in synergy with the news value of the image. Attitude is divided into 
"affect, judgment, and appreciation" (Martin and White, 2005). Affect is emotionally response. Judgment is evaluation of behaviour based on normative value. Appreciation focus is on how values being constructed toward something. Each category get extend classification. The classification can be something positive and negative. Martin and White (2005) make classification as stated in table 1.

Table 1: Notation in Appraisal

\begin{tabular}{|l|l|l|l|}
\hline Notation & Explanation & Category & Indicator \\
\hline+ & Negative & Attitude & Negative impact \\
\hline- & Positive & Attitude & Positive impact \\
\hline Des & Desire & Affect & How desire? \\
\hline Hap & Happiness & Affect & $\begin{array}{l}\text { How much feeling } \\
\text { happy? }\end{array}$ \\
\hline Sec & Secure & Affect & $\begin{array}{l}\text { How much feeling } \\
\text { secure? }\end{array}$ \\
\hline Sat & Satisfaction & Affect & $\begin{array}{l}\text { How much feeling } \\
\text { satisfied? }\end{array}$ \\
\hline Norm & Normality & Judgment & How special $?$ \\
\hline Cap & Capacity & Judgment & How capable? \\
\hline Ten & Tenacity & Judgment & How dependent? \\
\hline Ver & Veracity & Judgment & $\begin{array}{l}\text { How honest? } \\
\text { hew }\end{array}$ \\
\hline Prop & Propriety & Judgment & $\begin{array}{l}\text { How } \\
\text { reproach? }\end{array}$ \\
\hline Reac & Reaction & Appreciation & Affection \\
\hline Comp & Composition & Appreciation & Appreciation \\
\hline Val & Valuation & Cognition \\
\hline
\end{tabular}

\section{The value of image in news}

Image evaluation is adopted from the news value of photography in journalism. Caple (2013) divided some criterion on photojournalism image. The criterions are negativity, timeless, proximity, prominence, consonance, impact, novelty, superlativeness, personalization, and aesthetic. One image can contain several news values. Each category has parameter as Caple (2013) has set. Here are some guidelines to decide the value of image in news.

Table 2: News value in image

\begin{tabular}{|l|l|}
\hline News value & Explanation \\
\hline Negativity & negative aspect \\
\hline Timeless & time relevancy \\
\hline Proximity & the geographical and/or cultural nearness \\
\hline Prominence & the high status of the individuals \\
\hline Consonance & the extent to which aspects of a story fit in with a stereotypes \\
\hline Impact & the effects or consequences \\
\hline Novelty & the unexpected aspects \\
\hline Superlativeness & the maximized or intensified aspects \\
\hline Personalization & the personal or human interest aspects \\
\hline Aesthetic & beauty or aesthetic quality \\
\hline
\end{tabular}


After news value, the image which is the result of photography can be grouped by the type of the shot (Kress and van Leeuwen, 2006; Caple, 2013). The shot of photo can describe the social distance between viewer and image. Long-shot is the type of shot that capture all body of person plus the surrounding such as background scenery. Long-shot means the gap of interaction is impersonal. Middle-shot usually take a shot from half upper human body. Middle-shot means the interaction occurs in social distance. Close-up is the shot that takes close image such as the face of person. This kind of interaction means personal distance interaction.

\section{Ethic in Journalism}

Every work field has its own principle toward what they are doing and has criterion of what things are prohibited. It also occurs in journalism. There are some points to be considered in writing news text which is called journalism ethics and regulation. According to Keeble (2009), ethic in reporting news must be considering the accuracy, truthfulness, objectivity, neutrality, impartiality, and balance. Reporting news also need to consider the interest of reader toward issues and have social responsibility to public. Frost (2010) said in reporting news, journalist must take mind of truthfulness, morality, trust, accuracy, objective, balance and impartiality. The news cannot be harmful to public.

Ethic is a basis point which has to be done in reporting news. News cannot be completely neutral and objective but it is a must that writer need to deliver true news. News also needs to show the balance between one side of point of view to another. For example, in writing news that only taking sources to a pro side without take into account of contra side is the action that show imbalance and disadvantages to some party. Other consideration is the report need to keep the privacy of sources and it has to protect people. The news should not bring destruction to society or personal life. Not only in writing, but also is in the chosen picture in news also bringing the same duty in ethic.

\section{Data and Method}

The source of data is taken from CNN International web page. The text is published in Asian news column at 12 December 2016. The title of the news is Philippines President Duterte should be impeached for 'mass murder': critic. The article is about critic from several people such as activist and politician to President and his policy. Another reason the security topic is chosen since this topic appearance in CNN International website is quite high in number.

The method of this research is qualitative. The qualitative method here is including classification-explanation way in finding out the power-display of the text (Kamberelis dan Dimitriadis, 2005). This analysis is expected be able to comprehend the text and to find hidden message contained power relation. The research is limited to critical discourse analysis with multimodal approach. There are two modalities that are used; they are image and written text. In written text, language unit that used are from words, phrase, and simple clause. In addition for image, the type of image that being used is still image. The results from verbal and non-verbal analysis are represented in chart and graph to make easier to the reader in understanding the finding. Here presents in figure 1 the theoretical framework that assists how the method would work on this research. 


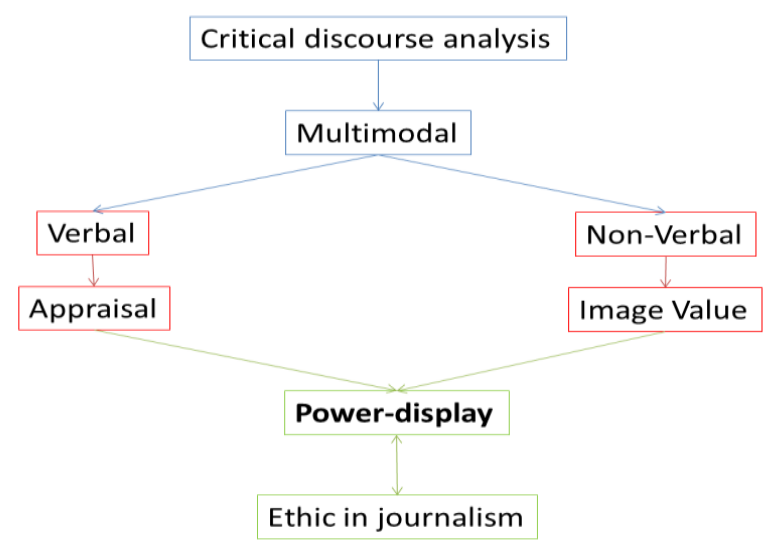

Figure 1: Theoretical Framework

\section{Finding and Discussion}

The finding is taken by two analysis; verbal and non-verbal. Analysis in verbal aspect finds out the distribution by the use of appraisal or meaning evaluation in finding attitude of language. While non-verbal analysis find out the image value from a text. Both findings get a cross-check to ethic in journalism as if the text fit to the ethics or if the text has deviation. The result can show how the power is being displayed through the text in a holistic view.

\section{Attitude of language}

To show how this research work. I present a part of analysis that has been collected and classified in table analysis of appraisal (Martin and White, 2005). The table analysis of appraisal stands for some columns such as number, appraiser, appraised, appraising item, affect, judgement, and appreciation. Appraising item is item (word, phrase, or clause) that contains the potential of attitude. Appraiser is a person or thing that makes an appraisal process to something. Appraised is the token of the attitude. One appraising item only has one attitude; it can be affect, judgement, and appreciation. The categorization process is taking consideration to the parameter stated before in the theory and is based in context. One item can be used in different attitude if the context is different. The first table has seven items which are evaluated. Meanwhile only two attitudes are found, they are affect and judgement.

Table 3: Evaluation of Attitude B1

\begin{tabular}{|l|l|l|l|l|l|l|}
\hline No & Appraising item & Appraiser & Appraised & Affect & Judgement & Appreciation \\
\hline 1 & mass murder & critics & Duterte & -sec & -- & -- \\
\hline 2 & critics & reporter & Duterte & -- & -ver & -- \\
\hline 3 & power & reporter & Duterte & -- & +cap & -- \\
\hline 4 & waged a brutal war & reporter & Duterte & -- & -prop & -- \\
\hline 5 & deaths & reporter & drug suspects & -sec & -- & -- \\
\hline 6 & accused & reporter & Duterte & -- & -ver & -- \\
\hline 7 & has enraged & admission & Duterte's critics & -sat & -- & -- \\
\hline
\end{tabular}

From the first item in table 3, the appraiser is critics and appraisal item is mass murder by President Duterte. Critics in item one appears as subject that is describing feeling of insecurity of someone and mass murder is the item that is being assessed. Moreover, critic also appears in item two. Critics in this item come from reporter assessment that means there is something wrong to be fixed. There is a judgement weighting in second item. Critics become something which is questioned so second item is categorized as negative veracity. By this case 
we can assume that a word can have different evaluation depend on who and how the words work to create meaning,

There is also positive evaluation that is in item three, "power". Power shows that there is capacity of President in doing his job to protect country. Here, the President is able to declare war toward illegal drug. However, item four has quite different case to item three. Item four shows how the positive capacity brings more harmful cause such as death. Death in this case is not natural being but the result of someone abusing power or by using the capacity. The word "death" is used to drug suspect as object of the act. Because of the suspect suffer the treat of death, they will feel insecure and it makes the evaluation become appraisal in affect criteria. The death also has similar case like what in item four has. Item four is waged a brutal war. The word "brutal" has relation to destroying something. Brutal war is identified as negative propriety as it violates the law.

The word "accused" is the sixth item which comes from reporter as appraiser to President Duterte as appraised. Accused is the form of judgement in negative veracity. The word "accused" makes someone get some responsibilities toward something he does not admit of. As veracity measure the honesty of someone, getting accused is an act that questioning the honesty side or the truth behind an act. This kind of judgement doubting the justice of Duterte doing. The last item in table one is the phrase "has enraged". The admission is appraising President Duterte with judgement of dissatisfaction by the appearance of the phrase "has enraged".

From collecting all the data not only from example in table 3 above, identified the affect, and organizing the result. It is revealed that the majority of the source of attitude intends to be in the opposite side of President. The side against President mostly come from politician in the country and activist of human right. While the part that is siding for President, is official government. Majority against the act of President and only a person defend what President or officer did as general. The imbalance of compositing the sources of a text is indicating the lack of balance and impartiality in ethic of journalism. The lack of balance of sources has been expected as it is a critical text and it is one of the strategies of the writer to create critic toward someone without getting involve by personal opinion but making its composition that favour or stand their point of view to against government.

Since all of the data stand for four parts (54 items), the evaluation can be drawn to diagram that shows the distribution of attitude. Here is the diagram of appraisal of the text as a whole in diagram 1. 


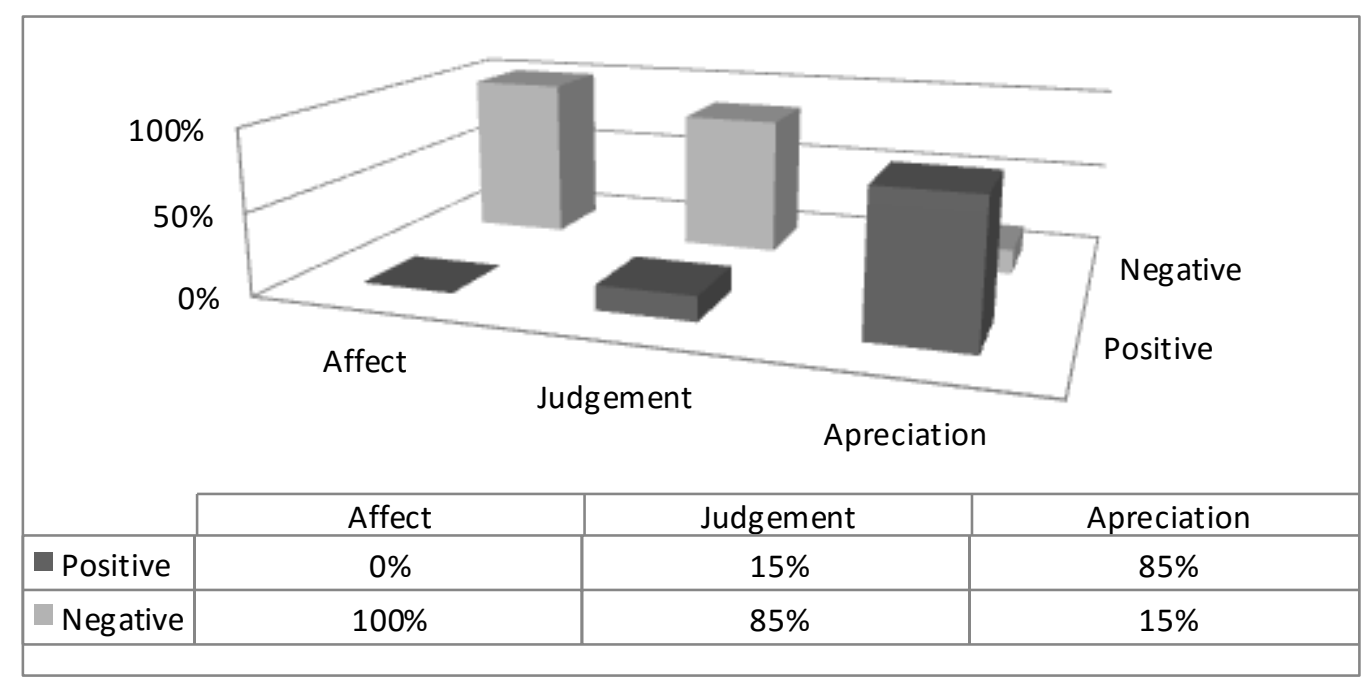

Diagram 1: Appraisal Positive and Negative (\%)

From the result drawn above, negative evaluation holds the big part in this text. The majority of negative aspect makes the ratio of attitude here are not balance. Moreover even in affect chart, the result is $100 \%$ negative. Judgement also has negative evaluation more than positive evaluation. Meanwhile appreciation has different result with having positive evaluation more than negative one. To see more detail in the distribution of attitude in this text, the chart below show judgement evaluation has hold big part followed by affect and appreciation by few.

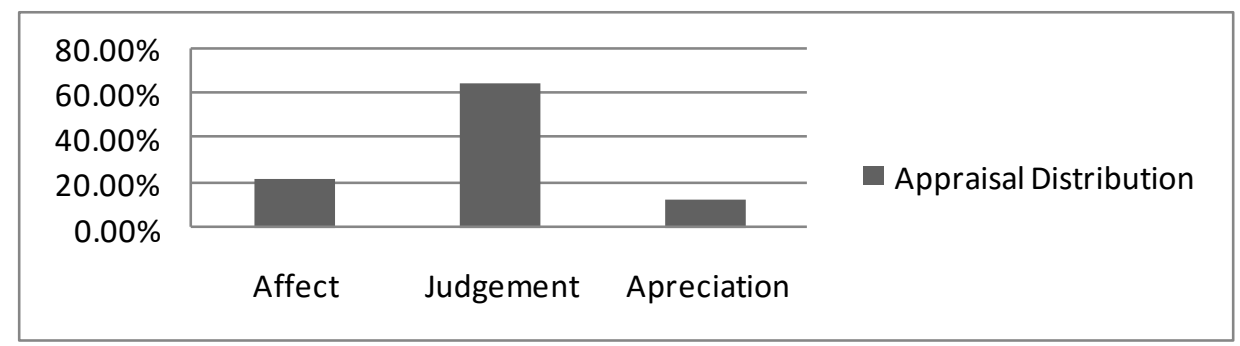

Diagram 2: Appraisal Distribution (\%)

The evaluation of affect in the diagram 3 shows all negative evaluation and nothing positive. The negativity in affect appears because the text contains insecurity aspects such as the feeling of unsafe and the lack of protection to citizen of The Philippines. This can affect the stereotype that the country as general is a risk to get there as it is not safe. The insecurity arises because the war of drug turns brutal and uncontrolled so innocence can be arrested and become a suspect. The evaluation of dissatisfaction and unhappiness also are in this text but hold a small part. The assessment here of course can bring disadvantage for the image of the country. 


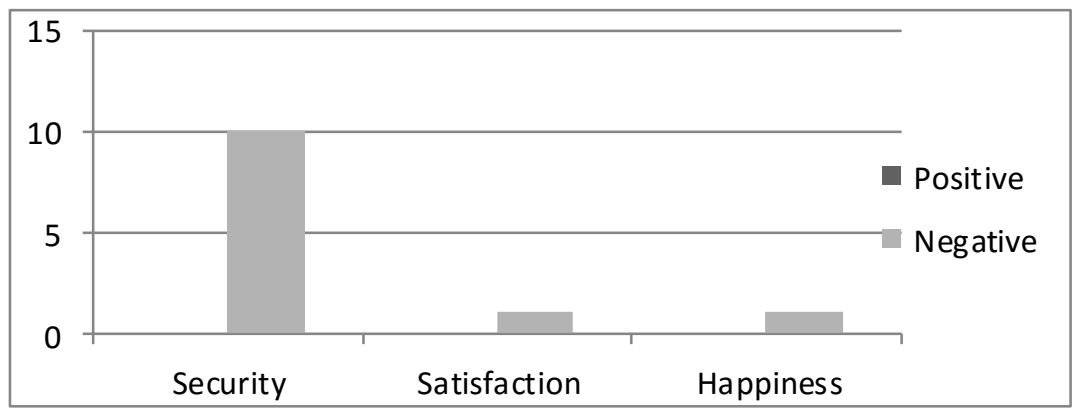

Diagram 3: Distribution of Affect

The distribution of judgment (Diagram 4) in this text shows the negative evaluation more than positive one. Only five items contains positive evaluation while the rest are negative. The domination of judgement is propriety. Since propriety evaluate the law and norm. It appears in the discussion about crime, killing and drug dealer. The big numbers of negative veracity are also attending in this text. It shows how honest, real and credible something to take into account. The other evaluation such as capacity, tenacity, and normality share some number of evaluations less than propriety and veracity. From the diagram, the text mainly discuss about legal issues. It can be concluded that the text purpose is describing the country's problem such as law enforcement and truthfulness of fact exposure.

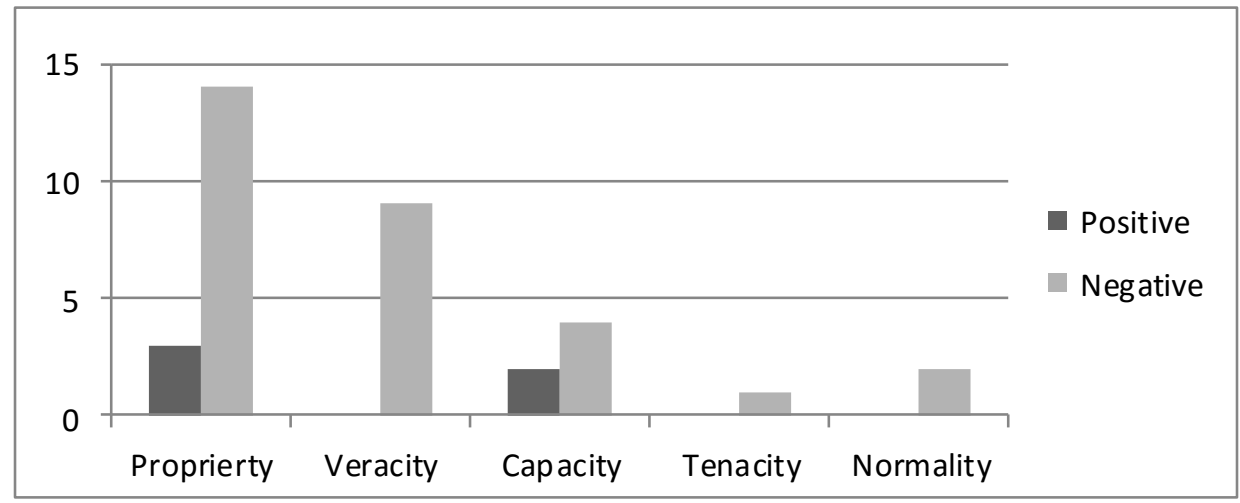

Diagram 4: Distribution of Judgment

Appreciation has the smallest number of evaluation in this text. Only two parameters appear that are reaction and valuation. This evaluation has more positive attitude than negative one. Positive attitude evaluate the President who are elected and received by citizen in fair election. The positive attitude also shows the support in war to drug by government. Appreciation here has two polar faces, one is the fact that President is elected and admired by citizen but on the other side the citizen are questioning the President's decision on how the war of drug had been done. 


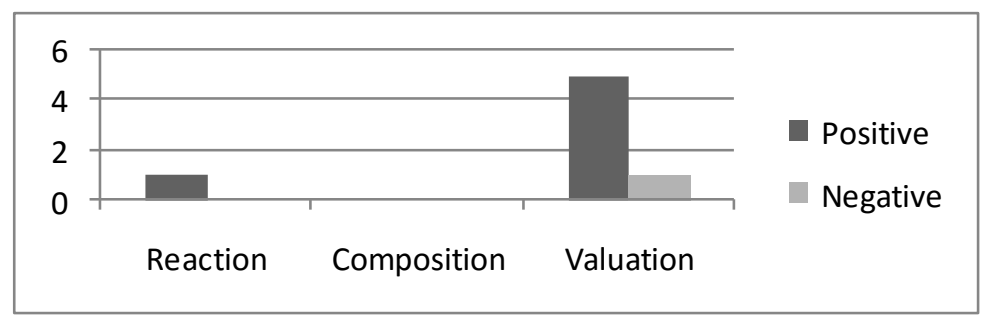

Diagram 5: Distribution of Appreciation

From appraisal analysis, it shows that news text about security critic is displaying more negative aspects more than positive one. There is the dominance of judgement in this text which is advisable to not use judgemental language in reporting an event. Text is composed more by showing critic toward law and power controlled by government. The text uses many sources to prove the statement as the ethic in journalism state that news must be objective. The strategy used here is doing critic without giving out personal opinion. Even though the writer try to gather many resources to encourage the statement and seems to be legit and objective, the writer has his specific goal of kind of text he want to deliver. The writer is creating the composition of sources that fit the expectation and point of view which has purpose to critic the bad side of government by showing more negative form of diction than positive ones.

\section{Image value of the text}

Text has 10 pictures that can be evaluated. The pictures stand from 9 photography images and one of diagram image. They are still images. The process of evaluation started by researcher shorting the image from the first to the last appear in the text then labeling the value of each image use the parameter stated in the theory. The pictures are being classified by its news value and shot type. For example the researcher shows one image and its value in Figure 3:

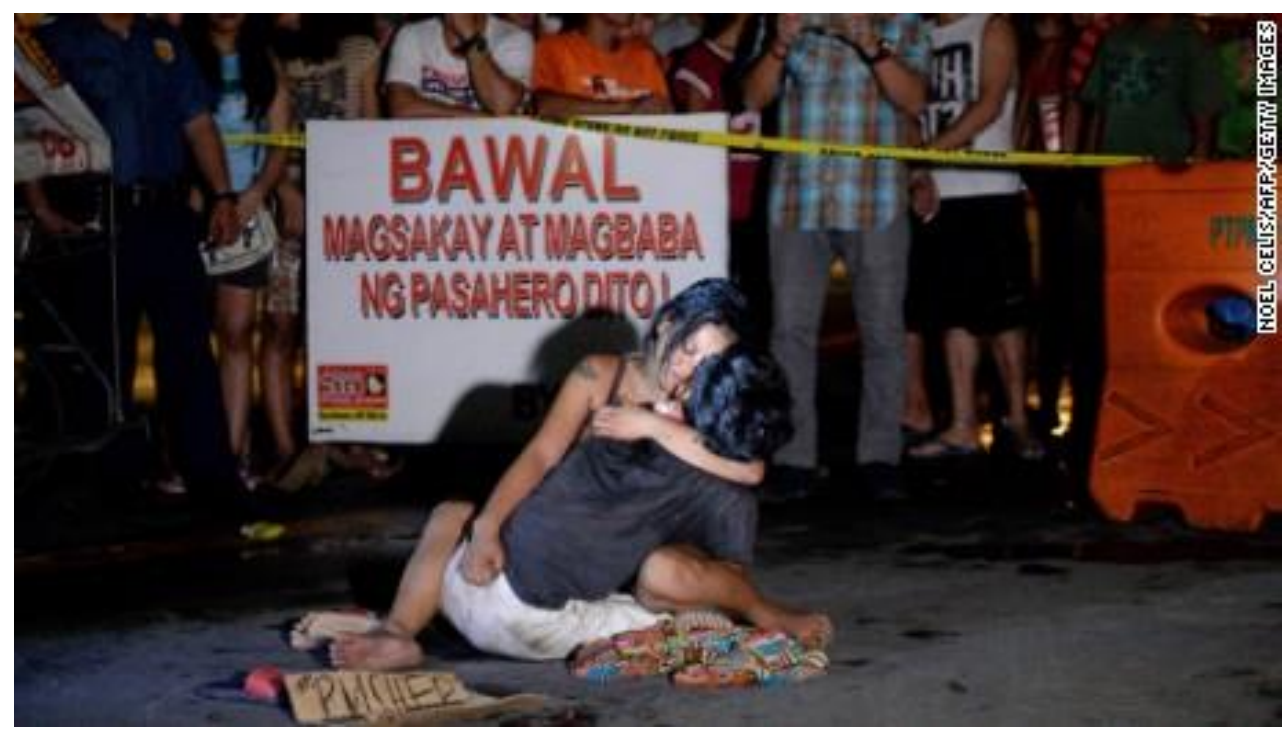

Figure 3: A woman cradles her husband, next to a placard which reads "I'm a pusher," who was shot dead in Manila on July 23, 2016. Published by CNN International 12.12.16

The picture in figure 3 alone cannot be interpreted without knowing the context of the event. This picture is a wife holding her husband on the lap. The husband was found death caused by a deadly police operation to drug dealer (pusher). The circumstance (place) is in the side of the street as it can be found the street mark behind that states bawal magsakay at magbaba ngpasahero dito! that means 'load and unload the passenger is prohibited here!'. This image values are novelty, impact, negativity and personalization. The novelty value indicates the 
dramatization of how the picture is taken. The impact is the death of someone because of police operation. The negativity here is the death, sadness, and sorrow. The personalization is the engagement of humanity aspect and people interaction displayed in the picture

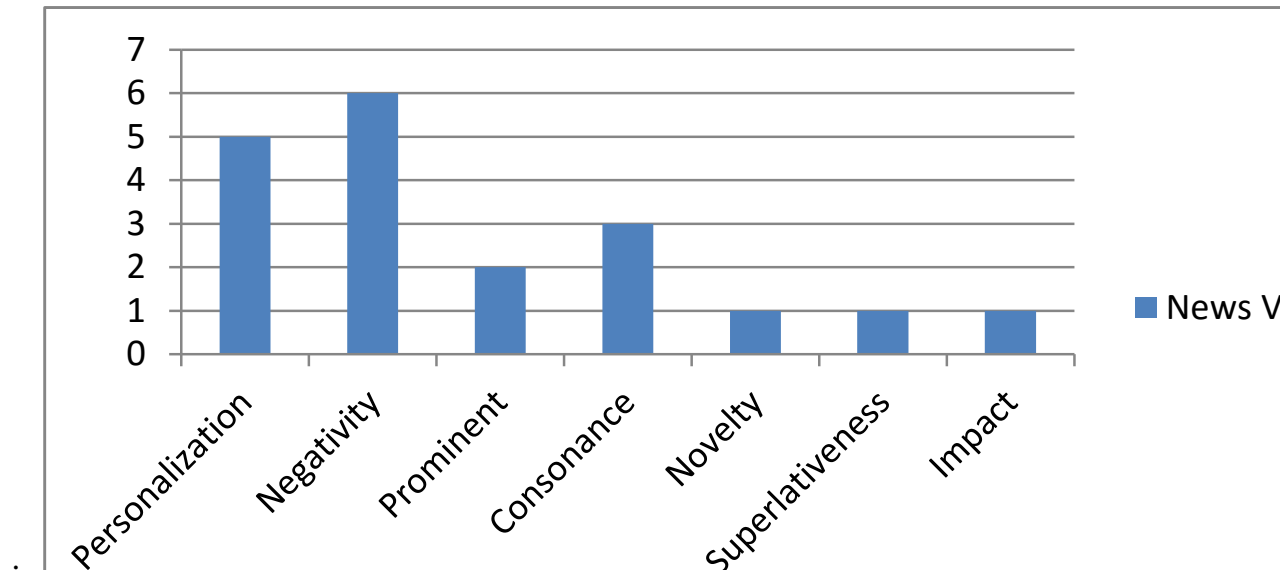

Diagram 4. Distribution of News Value

From all pictures that has been analysed, power-display in this research is editor wants to express sharp critics by including negative pictures related with human activity which is shown by personalization and negativity. The example of negative activity is killing person without juridical process. It has the linear relationship to written text that has negative assessment. However there are the differences between the written text and Image. The difference is the images display general people such as police and citizen, but the people in written text that being involved are specific by mentioning the names. Another difference aspect of image and written text is negative side of written text is represented by authority such as government, president, and official worker. Meanwhile negative side in image is displayed by civil, and criminal. The police is displayed as the authority whose done their job well, arresting the criminal, and patrolling the street. The government is presented by counsellor and as the rule in the country.

The type of dominant shot is medium and long shot. Medium and long shot means the editor place himself and viewer in impersonal and social distance (Caple, 2013). The shots means there is lessen personal involvement in image. It may be the cause of cultural and geographical gap between the image editor and the event taking place. That is why considering the text and background culture of editor, event, and viewer is a need. This kind of composition reminds viewer that they are not belonging to the event, except if the viewer is already involve or residence in the Philippines. But it doesn't makes the viewer may feel less sympathy to what had happened since the humanity aspect brings the feeling of sadness, madness and sorrow may be involved in some pictures.

\section{Conclusion}

Critical discourse analysis multimodal is one of the research tools of finding discursive message like ideology, hegemony, and power. This model has ability to gather modalities in data which contain several semiotic modes such as in online text. In critical text about security issue, the researcher find the similiarity of pattern in reporting news in both image and written modes. Both elements prioritized negative aspect of events. In written language, there is tendency of using proper name to refer the actor of the process. In nonverbal, the image captures human activity the most but instead by referring to the specific person, it is showing the general people or public. In reporting the news, it is found that the composition of the news sources is not balance between pro-government and anti-government. This situation is not benefiting the side that gets the critic.

The writer strategy is to be objective by reporting the true event that follows the ethic such as not personally getting involve in the text. However, he has role in choosing and composing ideas of many sources as his favour 
so that the article becomes a judgmental text. It is advised to writer and editor to become more neutral and to be fair in giving point of view. Another input is to serve more point of view of an event and let the readers choose what they want to believe. A critical text is good as input of reflection and introspection to the one that get the critic. Knowing how the text works in criticizing helps the reader to make a better understanding of the event, becomes more objective, and does not easily get provoke. There are still many aspects need to explore in multimodality such as combining gesture, oral language, and art work. There is hope that future researcher can make use of it in any field of study.

\section{References}

Afriliani, 2016, Critical discourse analysis of media: ISIS, Islam, and slavery. Proceeding of International Systemic Functional Conference $43^{\text {rd }}$ 2017, Bandung-Indonesia.

Afriliani, 2017a, Akses gambar dalam linguistik sistemik fungsional: memanfaatkan foto galeri sebagai pembelajaran otentik (Access to image in systemic functional linguistics: make use photo gallery as authentic learning). Proceeding of Pengajaran bahasa dalam perspektif lintas budaya. Depok, Indonesia, Faculty of Humanity Universitas Indonesia. pp. 27-37

Afriliani, 2017b, Power-display in News Text about issues in Regional Asia by CNN International: Critical Discourse Analysis Multimodal. Thesis. Depok, Indonesia, Faculty of Humanity Universitas Indonesia.

Baldry, A. \& Thibault, P.J., 2006, Multimodal transcription and text analysis (London, UK: Equinox).

Bazzi, S., 2009, Arab news and conflict: a multidisciplinary discourse study (Amsterdam \& Philadelphia: John Benjamins).

Berlinger,J., \& Boykoff, P.,2016. Alleged Duterte hitman denied protection after tell-all testimony. Date of Access: 16/9/2016 http://edition.cnn.com/2016/09/16/asia/philippines-edgarmatobato-duterte-hearing/

Caple, H., 2013, Photojournalism, a social semiotic approach. (London, UK: Palgrave macmillan).

Dolon, R. dan Todoli, J., 2008, Analysis of identities in discourse. (Amsterdam \& Philadelphia: John Benjamins).

Elleström, Lars, 2010. Media Borders, Multimodality and Intermediality. (New York, USA: Palgrave Macmillan).

Frost, C., 2010, Journalism ethics and regulation (Essex, UK: Pearson).

Griffiths, J, Philippines President Duterte should be impeached for 'mass murder': critic. Date of access 2/01/2017. http://www.cnn.com/2016/12/14/asia/philippines-duterte-leila-de-lima/

Halliday, M.A.K., 1994, An introduction to functional grammar (London, UK: Edward Arnold).

Kamberelis, George \& Dimitriadis, Greg., 2005, On qualitative inquiry, approaches to language and literacy research ( New York, USA: Teacher College Press).

Keeble, R., 2009, Ethics for journalist. (New York, USA: Routledge).

Kress, Gunther., 2010, Multimodality: a social semiotic approach to contemporary communication (New York, USA: Routledge).

Kress, Gunther \& van Leeuwen, Theo., 2006, Reading images: the grammar of visual design (2 ${ }^{\text {nd }}$ ed.) (New York, USA: Routledge).

Knapp, P., Watkins, M., 2005, Genre, Text, Grammar, technologies for teaching and assessing writing. (Sydney, Australia: University of New South Wales Press Ltd)

Knox J.S., Patpong P. \& Piriyasilpa Y., 2010), ข่าวหน้าหนึ่ง(Khao naa nung): A Multimodal Analysis of Thai-language Newspaper Front Pages". In New discourse on language: functional perspectives on multimodality, identity, and affiliation, edited by Bednarek, M. \& Martin, J.R. (London \& New York: Continuum), pp.80-110.

Machin, D. \& Mayr, A., 2012, How to do critical discourse analysis: a multimodal Introduction (London, U.K.: SAGE).

Martin, J.R. \& Rose, David, 2007. Working with discourse, meaning beyond the clause (2nd ed.). (London, U.K: Continuum). 
Martin, J.R. \& White, P.R.R., 2005, The language of evaluation: appraisal in english (New York, USA: Palgrave Macmillan).

McNair, B., 2006, Cultural Chaos; Journalism, news and power in a globalized world (New York, USA: Routledge)

Read, J., \& Carroll, J., 2012, Annotating expression of Appraisal in English. Language Resources and Evaluation, 46 (3), 421-447.

Thomson, E.A., White, P.R.R, \& Kitley, P., 2008, Objectivity and hard news reporting across cultures. Journalism Studies, 9(2), 212-228. 